TURIZAM

Volume 22, Issue 4

133-144 (2018)

ORIGINAL

SCIENTIFIC PAPER

\title{
Factors Affecting the Emotional Labor in Food Services - The Case of Van as a Tourism Destination
}

\author{
Ibrahim Cetin ${ }^{A}$, Onur Icoz ${ }^{B}$, Ayhan Gokdeniz ${ }^{\mathrm{C}}$ \\ Received: October 2018 | Accepted: December 2018 \\ DOI: 10.5937/turizam22-19040
}

\begin{abstract}
There are many studies on the concept of emotional labor in the literature, but limited studies available in the food services business. For this reason, the basic objective of present study is to identify the factors affecting emotional labor of employees in this industry and to explore the situational factors and demographic variables that may have an impact on emotional labor through its sub dimensions as surface acting and deep acting. The data were collected from the food services workers during 2017 summer season in Van, by a questionnaire as the survey instrument which was developed by the authors from the literature. Major findings of this survey can be summarized as; emotional labor was mostly influenced by emotional dissonance and interaction variety, and positive relationships were found between interaction frequency and interaction intensity, emotional dissonance and interaction variety; there is a significant association between intensity of interaction and gender of the employees; and as a demographic dimension, woman workers display more intensive emotional labor then men do.
\end{abstract}

Keywords: Emotional Labor, Food Services Business, Situational factors

\section{Introduction}

The most significant responsibility for effective service delivery in the food services operations belongs to the front line employees. As a marketing principle, the first step for effective customer satisfaction is to provide internal customer, namely employee satisfaction. While Kotler et al. $(2010,40)$ stated that employee selection, training and satisfaction can improve the internal service quality which is the foundation of creating a profitable service-value chain, it should be noted that satisfied employees also create much more effective service value, resulting satisfied and hence loyal customers.

Department of Tourism Management, Serik Faculty of Business, Akdeniz University, Turkey, ibrahimcetino1@yahoo.com

B Department of Travel Management, Faculty of Tourism, Adnan Menderes University, Turkey. Correspondent person: onur_icoz@hotmail.com

c Department of Tourism, Vocational School of Tourism and Hotel Management, Balikesir University, Turkey, aygokdeniz@ yahoo.com 
Service staffs are always in touch with the guests and any form of employee appearance and behavior, such as cleanliness, a positive mood, performing their job with a courtesy may have an impact on customer satisfaction. Emotion, on the other hand, is the tonal quality of all human behavior, which conveys the sense and motive of thought-speech-action, such as when front-line workers provide enthusiastic service, empathic care or even grudging assistance with an irritated tone (Barker 2001, 176). Hence, the need for management of employee feelings has also created a need for a well understanding the concept of emotional labor.

In this study, some of the factors affecting emotional labor were investigated in Van as an emerging tourism destination. The reason for this research is the fact that there are low number of studies about emotional labor in food services industry in small cities (Sharma et al., 2015; Srivastava, Srivastava, 2018; Tsaur et al., 2015). This study also aims to find out the some specific demographic variables that may have an impact on emotional labor.

\section{Literature Review}

The concept of emotional labor and its relevance to tourism and hospitality industry is well documented in the literature, and it refers to the requirement from employees to either dissemble or manage actual feelings for the benefit of successful service delivery (Pizam, Shani 2009; Pala, Tepeci, 2009). Likewise, Brook (2013) argues that service workplaces require high degree of emotional labor such as restaurants, cafes, hospitals, call-centers and retail stores, and emotional labor is specifically important in interactive service jobs (Leidner, 1999) due to the inconsistency between customer expectations and behavior. Customers always demand high-quality service from the staff irrespective of their behavior towards them. The intangible nature of services provided by the service staff make it hard for customers to appreciate the service quality offered (Augustine, Joseph, 2008).

Hochschild (1983) was the first author to introduce the evidence of emotional labor in everyday work roles. Since her study, emotional labor has become an area of research which gains increasing attention (Hwa, Amin, 2016). There have been various studies which have increased the emotional labor literature by providing theoretical and empirical support for this topic (Grandey, 200o; Brotheridge, Lee, 2003; Ang, Poh, 2013; Mahamad, 2014; Santos, et al. 2015). Emotional labor was specifically examined among flight attendants (Hochschild, 1989), Disneyland employees (Maanen, Kunda, 1989) and fast food workers (Leidner, 1993) as hospitality related areas besides many other disciplines.

The act of expressing socially desirable emotions during service transactions is the basis for emotional labor (Ashforth, Humphrey, 1993). The interaction emerging between the two elements as consumer and service providers requires the adaptation of output as an acceptable social behavior to the organizational goals. Some early studies explained that behaviors are guided by the 'invisible hand' of norms for appropriate behavior or expectations that are established by organizations (Brotheridge, Lee, 2003, 365). Organizational expectations determine not only the content and range of emotions to be displayed (Hochschild, 1983), but also the frequency, intensity and the duration that such emotions should be exhibited (Morris, Feldman, 1996). Giardini and Frese (2008), Grandey (2000) and Hochschild, (1983) emphasize the importance of emotional labor as an indicator closely linked to employee wellbeing. For some authors (Brotheridge, Lee, 2003), it is the central to employees' performance to accomplish the tasks. 
In most of these studies, there are some common expectations about the appropriate emotional reactions of employees concerning service transactions. These expectations demonstrate the range, intensity, and duration of emotions experienced by employees. Flight attendants, for instance, treat passengers cheerful and friendly, and nurses treat their patience empathetic and supportive (Ashforth, Humphrey, 1993). The employee performance in hospitality industry is much more influenced by emotional labor than any other service sector, due to intensity of customer turnover, urgency, variety of jobs. Managers expect their employees to present excellent behavior in the presence of customers to make positive emotional impressions and emotional performance becomes a criterion for staff performances (Lu et al., 2013).

Consequently, emotional labor can be seen as a tool to effectively manage emotions in order for employees to achieve organizational goals and to manage mood or anger towards a co-worker or a customer which could result in better work performance (Grandey, 200o) and the success of employee by enhancing their performance depends on successfully monitor, control and manage their emotions (Tosten, Toprak, 2017).

\section{Theoretical Background}

\section{Emotional Labor}

Morris and Feldman $(1996,987)$ define emotional labor as the effort, planning, and control needed to express organizationally desired emotion during interpersonal transactions. Goodwin, et al. (2011) consider that it is the display of employee feelings in a way to please their clients, or reflection of this mood by using different strategies. Emotional labor also entails "organizational display rules irrespective of one's felt emotions and requires employees to apply emotion regulation strategies at work" (Hochschild, 1983). Employees spend emotional resources to meet the emotional demands of their roles in anticipation of generating rewarding relationships with their components such as customers and co-workers (Ma et al., 2015). Glomb and Tews (2004) on the other hand, focus primarily on the behavioral expression and non-expression of felt or unfelt emotions. The authors claim that emotional labor is displayed in two ways. Firstly, it emerges as the expression of emotions, and secondly it may be seen as the non-expression of emotions in accordance with display rules (Thurau et al. 2006).

\section{Surface Acting and Deep Acting}

These two are the sub dimensions of emotional labor and surface acting refers to the strategy of hiding felt emotions to display the appropriate emotions required by work, whereas deep acting is considered as a process by which individuals attempt to alter their inner feelings ( $\mathrm{Li}$, Wang, 2016). Studies verify that surface acting is related to low job satisfaction and high stress levels, whereas deep acting represented a pattern of positive relationships with job satisfaction (Kammeyer et al., 2013) and deep acting leads to a reduction in stress (Humphrey et al. 2015). In other words, surface acting is false unfelt emotions, as deep acting is the modification of felt emotions so that true display of emotion will follow (Othman et al., 2008; Thurau et al. 2006). For some authors, emotional labor is a learned behavior, and a person may develop skills that enable the enactment of surface and deep acting (Ashforth, Fried, 1988) and developing the deep acting ability of employees can reduce the negative consequences of emotional labor (Sharma et al., 2015). 


\section{Emotional dissonance}

Hochschild (1983, 90) describes this term as keeping a difference between feeling and feigning that may act as a stressor independent of other organizational stressor and it happens when explained emotions meet feeling rule, or role expectations concerning to emotional expression. Hoffman and Bateson $(2001,252)$ also conceptualized emotional dissonance as a result of role disagreement, in which contact staff are required to conceal their true feelings and display a front to the customer. Emotional dissonance is also considered a type of role clash, which has been shown to be a key antecedent of emotional exhaustion and the workers who practice emotional dissonance will probably experience low level of job satisfaction (Lewig, Dolard, 2003).

\section{Methods and Data}

\section{Sample}

This study was designed as an explanatory research and conducted in the territory of Van located in East Turkey. The target population is made up of 500 employees working at the food service businesses in the area. Simple random sampling technique was used to draw the representative group from the target population by conducting questionnaire survey.

\section{Research Instruments}

For the purposes of this study and based on previous research (Brotheridge, Lee, 2003; Diefendorf et al., 2005; Gradley 2000; Uzumcu et al., 2017) the questionnaire as data collection tool was modified and adapted for this research. The questionnaire was structured as a form of 5 point Likert Scale, ranging from strongly agree (5) to strongly disagree (1) in response to the questions. The questionnaire consists of two parts, first part designed for the demographics of respondents and second part was organized to measure the potential factors affecting emotional labor. 243 fully completed questionnaires which are considered satisfactory as a representative sample (p:0,05) were processed through statistical software programme. The time frame and location of target groups are the major limitations of this study. The demographics of respondents show that the majority of the services staff were working at the minimum wage level and the employee turnover is very high in this business.

\section{Conceptual Model, Variables and Hypotheses}

The conceptual model designed for this research is displayed on the Figure 1. The model assumes that there are external and internal factors affecting the emotional labor of food services employees. These relationships among the factors previously discussed by several authors as mentioned in the literature review. In this model, deep acting and surface acting are considered as dependent variables, while interaction frequency, intensity, variety (external) and emotional dissonance (internal) as independent variables which may have an effect on dependent variables. Based on this model following hypotheses are listed;

$\mathrm{H}_{1}$ : Interaction frequency has a positive effect on the deep acts of employees

$\mathrm{H}_{2}$ : Interaction frequency has a negative effect on the surface acts of employees

$\mathrm{H}_{3}$ : Interaction intensity has a positive effect on the deep acts of employees 
$\mathrm{H}_{4}$ : Interaction intensity has a negative effect on the surface acts of employees

$\mathrm{H}_{5}$ : Interaction variety has a positive effect on the deep acts of employees

$\mathrm{H}_{6}$ : Interaction variety has a negative effect on the surface acts of employees

$\mathrm{H}_{7}$ : Emotional dissonance negatively effects the deep acts of employees

$\mathrm{H}_{8}$ : Emotional dissonance as an internal factor positively effects the surface acts of employees

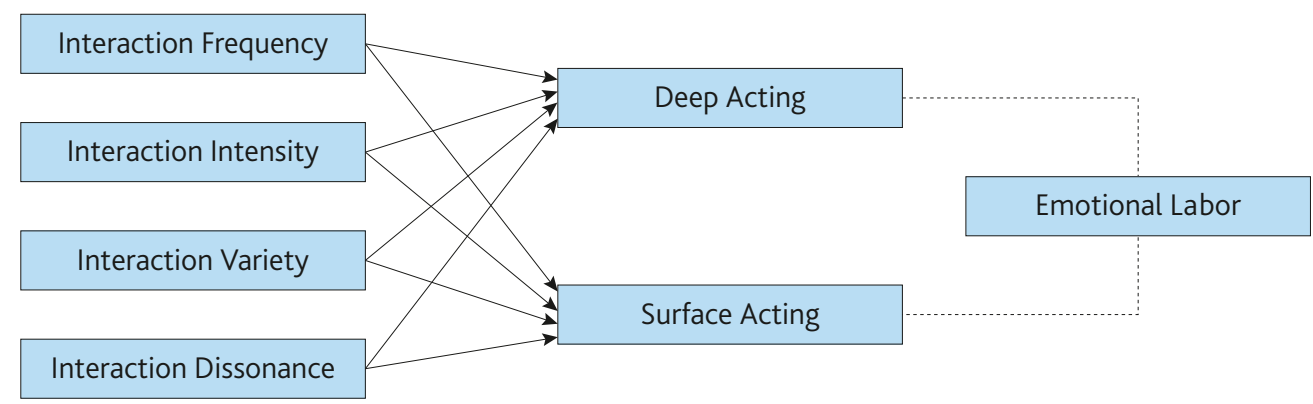

Figure 1. The conceptual model of the research

\section{Results and Discussion}

\section{Factor Analyses}

The data were processed and the items on the questionnaire were analyzed by confirmatory factor analysis. Kaiser-Mayer-Olkin (KMO) test value was found as 0.89 (>0.60) meaning the sample size is large enough for analyses, and Bartlett Test Value (p: o.oo) shows that there is no correlation between the variables. Cronbach's Alpha values indicate the reliability and internal consistency of the subscales of emotional labor. The alfa values show that the scale is highly reliable. Based on the results of exploratory factor analysis, the factor loads of 25 variables, and related 6 dimensions can be seen on Table 2. The results show that the items were accordingly distributed to the factors as required. The mean values for the subscale of emotional labor and its 6 dimensions. The results explain that the employees have mostly pointed out the scores less than 3 (3: undecided, 2: disagree, 1: strongly disagree) for these subscales. Hence, it was found that the employees often have negative emotions with their customer interactions.

Table 2. Confirmatory Factor Analyses

\begin{tabular}{|l|c|}
\hline Factors & Factor Loads \\
\hline Interaction frequency & 0.899 \\
\hline I interact with many customers on a daily basis. & 0.930 \\
\hline I interact very intensively with the customers on a daily basis. & 0.906 \\
\hline On a typical business day, I often have to meet with customers. & 0.654 \\
\hline It is the expression certain emotions as excited and enthusiasm is a part of my job. & \\
\hline Surface Acting & 0.728 \\
\hline I put on an act in order to deal with customers in an appropriate way & 0.725 \\
\hline I fake a good mood when interacting with the customers
\end{tabular}




\begin{tabular}{|l|c|}
\hline Factors & Factor Loads \\
\hline I put on a show or performance when interacting with customers & 0.742 \\
\hline I just pretend to have the emotions I need to display for my job & 0.829 \\
\hline I put on a mask in order to display the emotions I need for the job & 0.858 \\
\hline I fake the emotions I show when dealing with customers & 0.716 \\
\hline I show my feelings to customers that are different from what I actually feel & 0.740 \\
\hline Deep acting & 0.762 \\
\hline I try to experience the emotions that I must show to customers. & 0.786 \\
\hline I make an effort to feel the emotions that I need to display toward others. & 0.805 \\
\hline $\begin{array}{l}\text { I work hard to feel the emotions that are expected from me to show while } \\
\text { dealing with the customers }\end{array}$ & 0.842 \\
\hline I try to develop my feelings that I need to show to customers & 0.455 \\
\hline Emotional dissonance & \\
\hline $\begin{array}{l}\text { In order to satisfy organizational needs, I would deliberately express certain } \\
\text { emotions which I do not necessary feel }\end{array}$ & 0.715 \\
\hline $\begin{array}{l}\text { During my work hours, my external emotional expression is different from my } \\
\text { actual feeling }\end{array}$ & \\
\hline $\begin{array}{l}\text { My emotional expression is entirely based on the organizational requirement; it } \\
\text { is not my actual feeling }\end{array}$ & 0.705 \\
\hline $\begin{array}{l}\text { Sometimes, the organizationally required emotional expression differs from my } \\
\text { actual feeling }\end{array}$ & 0.790 \\
\hline $\begin{array}{l}\text { My actual emotions I feel when I interact with the customers are completely } \\
\text { different from my emotions I must display }\end{array}$ & 0.848 \\
\hline Interaction Intensity & 0.763 \\
\hline I express intense emotions & 0.753 \\
\hline I show some strong emotions & 0.709 \\
\hline Interaction Variety & 0.772 \\
\hline I express many different kinds of emotions & \\
\hline I display many different kinds of emotions & \\
\hline I display many different emotions when interacting with the customers \\
\hline
\end{tabular}

\section{Analysis of Variance}

One way ANOVA results on Table 3, represent significant differences between the ages of employees, their position, working hours, their professional experience and some of the emotional labor dimensions. The results of Least Significant Difference Test (LSD) also show that the middle aged employees (26-34) are doing their businesses with a more sincere, hearty and deeper feelings than younger ones (17-25). Likewise, the employees above middle age (35-44) pointed out higher scores for deep acting than younger employees (26-34), and they are also doing their businesses with a more sincere, natural and deeper feelings than those aged 26-34. Depending on the positions of employees in the workplace, the results of LSD show that assistant service employees display more intensive interaction than those in chef positions. 
Table 3. Analysis of Variance

\begin{tabular}{|c|c|c|c|c|c|c|}
\hline & Age & $\mathrm{N}$ & Mean & Std.Er & $\mathrm{F}$ & $P$ \\
\hline \multirow[t]{5}{*}{ Deep Acting } & $17-25$ & 181 & 3.098 & 0.098 & 2.720 & $0.045^{*}$ \\
\hline & $26-34$ & 53 & 3.104 & 0.186 & & \\
\hline & $35-44$ & 9 & 4.392 & 0.277 & & \\
\hline & TOTAL & $235^{*}$ & & & & \\
\hline & Position & $\mathrm{N}$ & Mean & Std.Er & $\mathrm{F}$ & $P$ \\
\hline \multirow[t]{6}{*}{ Interaction Intensity } & Waiter Assistant & 47 & 3.445 & 0.184 & 3.157 & $0.026 a$ \\
\hline & Waiter & 109 & 3.045 & 0.138 & & \\
\hline & Chef & 57 & 2.638 & 0.179 & & \\
\hline & Administrative Positions & 13 & 3.235 & 0.329 & & \\
\hline & TOTAL & $226^{*}$ & & & & \\
\hline & Shifts & $\mathrm{N}$ & Mean & Std.Er & $\mathrm{F}$ & $P$ \\
\hline \multirow[t]{6}{*}{ Emotional Dissonance } & $<8$ & 6 & 4.150 & 0.330 & 3.403 & $0.019 a$ \\
\hline & 8 hours & 35 & 4.100 & 0.227 & & \\
\hline & $8-10$ hours & 118 & 3.343 & 0.126 & & \\
\hline & 10 hours + & 84 & 3.415 & 0.148 & & \\
\hline & TOTAL & 243 & & & & \\
\hline & Work experience & $\mathrm{N}$ & Mean & Std.Er & $\mathrm{F}$ & $\mathrm{P}$ \\
\hline \multirow[t]{6}{*}{ Deep Acting } & $>1$ & 131 & 3.765 & 0.123 & 4.651 & $0.00 \mathrm{~b}$ \\
\hline & 1 year & 31 & 2.697 & 0.220 & & \\
\hline & $1-3$ years & 42 & 3.092 & 0.268 & & \\
\hline & $3-5$ years & 9 & 3.600 & 0.367 & & \\
\hline & $>5$ & 26 & 3.838 & 0.262 & & \\
\hline & TOTAL & $239 *$ & & & & \\
\hline \multirow[t]{6}{*}{ Surface Acting } & $>1$ & 133 & 3.361 & 0.134 & 4.596 & $0.002 \mathrm{~b}$ \\
\hline & 1 year & 31 & 2.533 & 0.276 & & \\
\hline & $1-3$ years & 42 & 2.398 & 0.227 & & \\
\hline & $3-5$ years & 7 & 2.464 & 0.896 & & \\
\hline & $>5$ & 28 & 3.369 & 0.278 & & \\
\hline & TOTAL & $241^{*}$ & & & & \\
\hline
\end{tabular}

Significant at $0.05^{(a)}, 0.01^{(b)}$

$\left(^{*}\right)$ There are some missing responses in these sections. However, over 217 sample size $(f \circ r=0.05)$ is acceptable.

Other different results were identified for the relationship between the emotional dissonance of employees and their job performance based on their daily working hours. The employees working 8 hours a day represent more complex emotional dissonance than others do. Similarly, the employees working 10 hours or more a day feel low emotional dissonance than those employees working 8 hours. This was an unexpected result, because it is normal to expect that the shorter the staff work, the less emotional dissonance they feel.

Finally, the results show that the experience in the job had an effect on the deep acts and surface acts of employees and this research clearly states that the longer the period employees work, the deeper acts they display and the longer the period employees work, the more surface acts they display. 


\section{Correlation analysis}

The correlation analysis matrix in Table 4 explains that there are significant positive associations between all dimensions except for the association between interaction frequency and surface acting, due to the statistically insignificant values.

Table 4: Correlation Analysis

\begin{tabular}{|l|c|c|c|c|c|c|}
\hline & I.Frequency & I.Intensity & S.Acting & D.Acting & I.Variety & E.Dissonance \\
\hline Interaction Frequency & 1 & & & & & \\
\hline Interaction Intensity & 0.544 & 1 & & & & \\
\hline Surface Acting & 0.065 & 0.245 & 1 & & & \\
\hline Deep Acting & 0.436 & 0.593 & 0.459 & 1 & & \\
\hline Interaction Variety & 0.523 & 0.673 & 0.462 & 0.678 & 1 & \\
\hline Emotional Dissonance & 0.499 & 0.537 & 0.581 & 0.647 & 0.640 & 1 \\
\hline
\end{tabular}

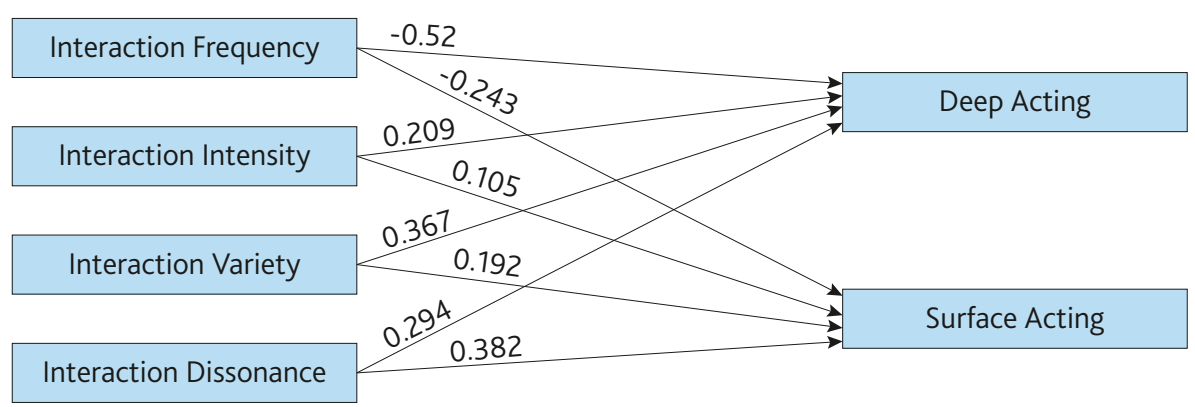

Figure 2. Research model test and full relationships

\section{Regression Analysis}

Based on the (linear multiple) regression analyses, all the relationships between the variables are shown on Figure 2 and in the below equations (1 \& 2). In these equations, deep acting and surface acting are considered as dependent variables, while others are (independent) parameters.

(1) Deep Acting = 0.697 (Constant) $-(0.52 \times$ Interaction Frequency $)+(0.209 \times$ Interaction Intensity $)+(0.367 x$ Interaction Variety $)+(0.294 x$ Emotional Dissonance $)$.
R: 0.702
$\mathbf{R}^{2}: 0.493$
$\mathbf{F}_{4,185 ; 70.592}$
p: 0.001

According to the regression analysis results for deep acting, approximately $50 \%$ of the change in emotional labor were explained by situational factors. The remaining $50 \%$ is explained by other factors which are not included into this study. Among the situational factors, interaction variety was the most effective parameter on the deep acts of employees in their interactions with the guests. Emotional dissonance was found as the second powerful factor affecting deep acting, while interaction intensity was the third. Regression analyses show that there is no positive effect of interaction frequency on the performance of emotional labor, contrary to other variables. This variable has a negative (-o.52) effect on the deep acts of employees. 
Regression analyses results also explain that any increase in interaction variety may have a somewhat high level of positive effect on the deep acts of the employees. However, the deep acts of employees are not only affected by interaction variety, but also by the other factors which were not included into the research model.

The results of hypotheses tests for deep acting are highlighted as the following;

- A reverse relationship (-0.52) was found between interaction frequency and deep acts of employees. Contrary to hypothesis $1\left(\mathrm{H}_{1}\right)$ interaction frequency has a negative effect on deep acting. Therefore, $\mathbf{H}_{\mathbf{1}}$ is rejected.

- Interaction intensity has a positive effect (0.209) on the deep acts of the employees. $\mathbf{H}_{3}$ is retained.

- $\quad$ Interaction variety has a positive effect (o.367) on deep acting with relatively reliable statistical values as hypothesized. Based on these results, $\mathbf{H}_{5}$ is retained.

- $\quad$ Contrary to hypothesis 7, emotional dissonance, as an internal factor positively effects (o.294) deep acting. Therefore, $\mathbf{H}_{7}$ is rejected. The statistical values show that the result is reliable and this relationship needs to be investigated with a larger audience group.

Based on the multiple regression results, the regression equation for surface acting can be written as;

(2) Surface Acting $=1.656$ Constant $-(0.243 x$ Interaction Frequency $)+(0.105 x$ Interaction Intensity $)+(0.192 x$ Interaction Variety $)+(0.382 x$ Emotional Dissonance $)$

$\mathbf{R}: 0.496 \quad \mathbf{R}_{2}: 0.246 \quad \mathbf{F}_{4,185} ; 70.592 \quad$ p: 0.001

This equation explains the weight of situational factors on surface acting. The regression analysis results for deep acting explain that almost $25 \%$ of the change in emotional labor was determined by the situational factors of surface acting. The remaining $75 \%$ might be explained by other factors. Among these determinants, emotional dissonance is the most effective parameter on the surface acts of employees. Among other factors, interaction frequency was the second effective factor on the surface acts of employees, while interaction variety was the third and interaction intensity was the fourth factor, which had the lowest level impact on this dimension. Emotional dissonance on the other hand, was a relatively more effective factor on the performance of the emotional labor in comparison to other factors with its 0.382 coefficient value.

The noteworthy results of hypotheses tests for deep acting are listed as the following;

- There is a negative relationship (-0.243) between interaction frequency and surface acting, as hypothesized. Interaction frequency has a negative effect on the surface acting. $\mathbf{H}_{\mathbf{2}}$ is retained.

- Interaction intensity has a slightly positive effect (0.101) on surface acting, as opposed to hypothesis $4 . \mathbf{H}_{\mathbf{4}}$ is rejected, but the results are not statistically meaningful, because of higher p values (0.194).

- Interaction variety as an external factor has a slightly positive effect (o.192) on the surface acts of employees, contrary to hypothesis 6 . Therefore, $\mathbf{H}_{\mathbf{6}}$ is rejected, but the results are not statistically meaningful as well.

- As initially hypothesized, emotional dissonance as an internal factor positively effects (o.382) the surface acts of employees with statistically meaningful values. $\mathbf{H}_{\mathbf{8}}$ is retained. 


\section{Conclusion}

The present study advances the literature on the use of the two dimensions of emotional labor and its subscales for the food services industry in Van, as a newly emerged Turkish tourism destination. The current study also contributes to the ongoing debate regarding external and internal factors affecting emotional labor. Thus, this study addresses a gap in the literature about emotional labor and its dimensions specifically in the food services business. This study also confirms a previous theory suggesting the potential relationships between emotional labor and the related situational factors or parameters.

Based on the multiple regression analyses, important findings that resulted from this research demonstrate that the most important factors affecting emotional labor and work performance through its sub dimensions are emotional dissonance and interaction variety. As another prominent finding of this research, correlations analyses show that there are meaningful associations between the majority of variables excluding interaction frequency and surface acting.

Previous studies revealed that service workplaces require high degrees of emotional labor, such as restaurants, cafes, hospitals, call-centers and retail stores, and emotional labor is specifically important in interactive service jobs as discussed earlier. This phenomenon was studied on flight attendants, theme park staff and fast-food workers and following this research evidence, the current study examined the food services businesses specifically confirming the relative importance of emotional labor for the job performance of employees with its dimensions.

From a practical standpoint, this study provides valuable information for the managers involved, in two specific areas. First, the managers should be careful about especially the factors of emotional dissonance and interaction variety. Perhaps, there may be some policies to develop the interaction variety as an external factor, but it may not be easy to find effective solutions about emotional dissonance due to its inner nature. Secondly, the analysis explains that there is a significant correlation between the dimension of intensity of interaction and gender of the employees. Results also show that female employees display more intensive emotional labor than males do. Therefore, it is recommended that the managers of hospitality and food services businesses should be careful about not only employees' physical health but also their emotional and psychological health. Because, they will need a work environment where they feel happy.

\section{Future research directions}

Present study provides some initial insights, and we are hopeful that the results can be useful for many tourism businesses and will be an interesting study and research area for the academicians who are involved. Undoubtedly, this study had many limitations as mentioned previously. Therefore, the findings cannot be generalized to the industry as a whole and they might be valid for only the locations alike. For further studies, we can suggest more detailed investigations covering larger geographic areas, with larger representative samples and different types of food services operations. Moreover, if some studies compare different types of businesses or sectors, it will be possible to develop working conditions of services sector employees in terms of both their physical and emotional labor. 


\section{References}

Ang, M., Poh, H. 2013. Providing "service with a smile": An Empirical Investigation of Labuan's Service Sector. In Baba, R. (Ed.), Labuan as an International Business and Financial Center: The Empirical Perspective. Pearson.

Ashforth, B., Humphrey, R. 1993. Emotional Labor in Service Roles: The Influence of Identity. Academy of Management Review 18(1), 88-115.

Ashforth, B., Fried, Y. 1988. The Mindlessness of Organizational Behaviors. Human Relations 41(4), 305-29.

Augustine, S., Joseph, B. 2008, Emotional Labor among the Frontline Employees of the Hotel Industry in India, In Jauhari, V. (Ed.), Global Cases on Hospitality Industry. Haworth Press.

Barker, C. 2001. Fear, Laughter, and Collective Power: The Making of Solidarity at the Lenin Shipyard, Gdansk, Poland. In Goodwin, J., Jasper, J., Polletta, F. (Eds.) Passionate Politics: Emotions and Social Movements. University of Chicago.

Brook, P. 2013. Emotional Labor and the Living Personality at Work: Labor Power, Materialist Subjectivity and the Dialogical Self. Culture and Organization 19(4), 332-352.

Brotheridge, C., Lee, R. 2003. Development and Validation of the Emotional Labor Scale. Journal of Occupational and Organizational Psychology 76(3), 365-379.

Diefendorf, J., Croyle, M., Robin, H., Gosserand, R. 2005. The Dimensionality and Antecedents of Emotional Labor Strategies. Journal of Vocational Behavior 66(2), 339-357.

Giardini, A., Frese, M. 2008. Linking Service Employees' Emotional Competence to Customer Satisfaction: A Multilevel Approach. Journal of Organizational Behavior 29(2), 155-170."

Glomb, T., Tews, M. 2004. Emotional labor: A Conceptualization and Scale Development. Journal of Vocational Behavior 64(1), 1-23.

Goodwin, R., Groth, M., Frenkel, S. 2011. Relationships between Emotional Labor, Job Performance and Turnover. Journal of Vocational Behavior 79(2), 538-548.

Grandey, A. 200o. Emotion Regulation in the Workplace: A New Way to Conceptualize Emotional Labor. Journal of Occupational Health Psychology 5(1), 95-110.

Hochschild, A. 1983. The Managed Heart: Commercialization of Human Feeling. University of California Press. Berkeley. CA.

Hochschild, A. 1989. Reply to Cas Wouter's Review Essay on the Managed Heart. Theory, Culture and Society 6(3), 439-445.

Hoffman, D., Bateson, J. 2002, Essentials of Services Marketing Concepts, Strategies and Cases. $2^{\text {nd }}$ Edition, Harcourt College Publishers.

Humphrey, R., Ashforth, B., Diefendorff, J. (2015). The Bright Side of Emotional labor. Journal of Organizational Behavior 36, 749-769.

Hwa, M., Amin, H. 2016. Why Emotion at Work Matters: Examining the Influence of Emotional Labor and Emotional Intelligence on Workplace Behaviors Among Service Workers in East Malaysia. Kajian Malaysia 34(1), 79-105.

Kammeyer, J., Rubenstein, A., Long, D., Odio, M., Buckman, B., Zhang, Y., Halvorsen-Ganepola, M. 2013. A Meta-Analytic Structural Model of Dispositional Affectivity and Emotional Labor. Personnel Psychology 66(1), 47-90.

Kotler, P, Bowen, J., Makens, J. 2010. Marketing for Hospitality and Tourism Industry. Pearson Prentice Hall. New Jersey.

Leidner, R. 1993. Fast food, fast talk: Service Work and the Routinization of Everyday Life. Berkeley: University of California Press. 
Leidner, R. 1999. Emotional Labor in Service Work. The Annals of the American Academy of Political and Social Science 561(1), 81-95.

Lewig, K., Dollard, M. 2003. Emotional dissonance, emotional exhaustion and job satisfaction in call center workers. European Journal of Work and Organizational Psychology 12(4), 366-392.

Li, M., Wang, Z. 2016. Emotional Labor Strategies as Mediators of the Relationship between Public Service Motivation and Job Satisfaction in Chinese Teachers. International Journal of Psychology 51(3), 177-184.

Lu, C., Shih, Y., Chen, Y. 2013. Effects of Emotional Labor and Job Satisfaction on Organizational Citizenship Behaviors: A Case Study on Business Hotel Chains. The International Journal of Organizational Innovation 5(4), 165-176

Ma, S., Silva, G., Trigo, V., Callan, V. 2015. Do Job Positions Matter in Emotional Labor and in Its Relationship with Job Performance? 11th European Conference on Management Leadership and Governance. November 12-13, Lisbon.

Mahamad, T. 2014. Understanding and Managing Malaysian Academics Emotional Labor. International Proceedings of Economics Development and Research 70(1), 76-80.

Morris, J., Feldman, D. 1996. The Dimensions, Antecedents and Consequences of Emotional Labor. Academy of Management Review 21(4), 986-1010.

Othman, A., Abdullah, H., Ahmad, J. 2008. Emotional Intelligence, Emotional Labor and Work Effectiveness in Service Organizations: A Proposed Model. The Journal of Business Perspective 12(1), 31-42.

Pala, T., Tepeci, M. 2009. Emotional labor level of the employees working in tourism operations and the effects of emotional labor on the attitudes of employees. Osmangazi University, Proceedings of 17th Congress on National Organization and Management. 113-119 (in Turkish)

Pizam, A., Shani, A. 2009. The Nature of the Hospitality Industry: Present and Future Managers' Perspectives, Anatolia: An International Journal of Tourism and Hospitality Research 20(1), 134-150.

Santos, A., Mustafa, M., Terk, C. 2015. Trait Emotional Intelligence, Emotional Labor, and Burnout among Malaysian HR Professionals. Management Research Review 38(1), 67-88.

Sharma, A., Banerjee, P., Yadav, R., Dash, S. 2015. Emotional Labor in Interactive Service Roles in Indian Restaurants, Indian Journal of Industrial Relations 51(2), 338-350.

Srivastava, P., Srivastava, S. 2018. Emotional Labor within Hotel Industry, A Case Study of Hotels in Ranchi, International Journal of Management Studies ISSN (Online), 2231-2528.

Thurau, T., Groth, M., Paul, M., Gremler, D. 2006. Are All Smiles Created Equal? How Emotional Contagion and Emotional Labor Affect Service Relationships, Journal of Marketing $70(3), 58-73$.

Tosten R., Toprak M. 2017. Positive Psychological Capital and Emotional Labor: A study in Educational Organizations, Cogent Education 4(1), 1301012.

Tsaur, S., Luoh, H., Syue, S. 2015. Positive emotions and behavioral intentions of customers in full-service restaurants: does aesthetic labor matter? International Journal of Hospitality Management 51,115-126.

Uzumcu, T., Gunsel, A., Yavas, A. 2017. The Consequences of Internal Marketing Activities on Emotional Labor in Tourism Industry, Journal of Human Sciences 14.(2), 1909-1923.

Van Maanen, J., Kunda, G. 1989. Real Feelings: Emotional Expression and Organizational Culture. In Cummings, L., Shaw, B. (Eds.) Research in organizational behavior. Greenwich. JAI Press. 